\title{
Does Evolocumab, as a PCSK9 Inhibitor, Ameliorate the Lipid Profile in Familial Hypercholesterolemia Patients? A Meta-Analysis of Randomized Controlled Trials
}

\author{
Seyyed Majid Eslami ${ }^{\mathrm{a}}$, Shekoufeh Nikfar ${ }^{\mathrm{b}, \mathrm{c}}$, Maryam Ghasemi ${ }^{\mathrm{a}}$, Mohammad Abdollahi ${ }^{\mathrm{a}, \mathrm{d}}$ \\ aToxicology and Diseases Group, Pharmaceutical Sciences Research Center, Tehran University of Medical Sciences, Tehran, \\ Iran. ' Evidence-based Medicine Group, Pharmaceutical Sciences Research Center, Tehran University of Medical Sciences, \\ Tehran, Iran. 'Department of Pharmacoeconomics and Pharmaceutical Administration, Faculty of Pharmacy, Tehran \\ University of Medical Sciences, Tehran, Iran ${ }^{\mathrm{d} D e p a r t m e n t}$ of Toxicology and Pharmacology, Faculty of Pharmacy, Tehran \\ University of Medical Sciences, Tehran, Iran.
}

Received, November 15, 2016; Revised, January 30, 2017; Accepted, March 3, 2017; Published, April 7, 2017.

\begin{abstract}
Proprotein convertase subtilisin-kexin type 9 (PCSK9) is a member of regulatory serine proteases which is mostly expressed in liver. In the physiological condition, LDL-C binds to LDL receptors (LDLRs) and via endocytosis, LDLRs are degraded. PCSK9 binds to the epidermal growth factor-like repeat A (EGFA) domain of extracellular LDLRs, and then physiological recycling of LDLRs from surface of liver is cancelled, resulting in elevation of circulating LDL-C in plasma. To evaluate whether evolucomab, as PCSK9 inhibitor monoclonal antibody, ameliorates lipid profile in familial hypercholesterolemia $(\mathrm{FH})$ patients, this meta-analysis has been conducted. PubMed, Web of Science (ISI) and Scopus databases were searched for studies which had investigated the efficacy of evolucomab. Types of outcome investigated were percentage changes from baseline of the lipid profile. Our meta-analysis shows that evolucomab at the dosage of $420 \mathrm{mg}$ monthly could decrease LDL-C by $54.71 \%$, TC by $35.08 \%$, VLDL-C by $28.37 \%$, ratio of TC to HDL-C by $39.14 \%$, triglycerides by $12.11 \%$, and increased HDL-C by $6.06 \%$ from baseline compared to placebo at the end of study in FH patients. Our findings indicate that evolocumab could be a hopeful agent for challenging patients, such as statin intolerance or patients who fail to attain the target goal of LDL-C despite consumption of maximum doses of statins.
\end{abstract}

This article is open to POST-PUBLICATION REVIEW. Registered readers (see "For Readers") may comment by clicking on ABSTRACT on the issue's contents page.

\section{INTRODUCTION}

Familial hypercholesterolemia (FH), the most prevalent inherited disorder, leads to elevations in low-density lipoprotein cholesterol (LDL-C) (1). The predominant underlying reason for $\mathrm{FH}$ refers to LDL-C receptors (LDLRs), which over 1288 variants of them have been identified and $79 \%$ of these are susceptible to cause disease (2). Initially, it was thought that $\mathrm{FH}$ is due to enhanced cholesterol synthesis, but nowadays it is known that catabolic rate of LDL is diminished (3). In heterozygous FH $(\mathrm{HeFH})$, single allele defect leads to moderate accumulation of plasma LDL, while homozygous $\mathrm{FH}(\mathrm{HoFH})$ with defect in both of alleles, leads to severe accumulation of plasma LDL without LDL cholesterol clearance. Enhanced circulating LDL-C gradually develops cardiovascular diseases. Mutation in genes which codes for LDLRs, apolipoprotein B and proprotein convertasesubtilisin-kexin type 9 (PCSK9) causes impaired elimination of LDL-C from the plasma (4, 5).

PCSK9 is a member of regulatory serine proteases which are involved in a broad spectrum of physiologic processes (6). It is mostly expressed in liver and less in kidney, small intestine, and central nervous system (7). This protease is secreted to plasma, existing in free form or associated with plasma proteins (8). PCSK9 affects cholesterol level by altering the number of available LDLRs in the surface of hepatocytes $(9,10)$. In the physiological condition, LDL-C binds to LDLRs and via endocytosis, LDLRs are degraded by lysosome.

Corresponding Author: Prof. Mohammad Abdollahi; Faculty of Pharmacy and Pharmaceutical Sciences Research Center, Tehran University of Medical Sciences, Tehran, Iran; E-mail: Mohammad@TUMS.Ac.Ir 
PCSK9 binds to the epidermal growth factor-like repeat A (EGFA) domain of extracellular LDLRs, and then physiological recycling of LDLRs from surface of liver is cancelled, resulting in elevation of circulating LDL-C in plasma (11-13). It has been observed that lacking PCSK9 in mice causes an increase in LDLRs reserving for LDL-C (14). Mutations, leading to gain of function in PCSK9, give rise to elevation in LDL-C and subsequently increase the cardiovascular events, while loss of function mutations cause diminution in LDL-C, leading to a reduction in coronary heart disease (15). The expression of PCSK 9 gene is controlled by intracellular cholesterol content (16). Therefore, cholesterol depletion through treatment with statins, ezetimibe and bile acid-binding resins, leads to PCSK9 upregulation (17-21). The transcription of PCSK9 and LDLRs are co-upregulated through the sterol regulatory element binding protein-2 (SREBP 2) pathway after treatment with statins and this reduces the therapeutic trait of statins $(22,23)$. Thus, statin treatment increases circulating PCSK9 levels additionally increases the content of LDLRs, explaining why doubling a statin dose, results in only
6 percent added decrement in the level of LDL-C in plasma (24).

On the basis of this evidence, inhibition of PCSK 9 by monoclonal antibodies seems to be an impressive approach to reduce LDL-C, mainly in the cases of intolerance or unable to attain desired LDL$\mathrm{C}$ level with statins. Evolocumab, bococizumab and alirocumab as PCSK9 inhibitor monoclonal antibodies are under development and in clinical trials.

Evolocumab (commercial name - Repatha ${ }^{\mathrm{TM}}$ ) has recently received the approval by the US Food and Drug Administration (FDA) and the European Medicines Agency (EMA), as a therapeutic agent for $\mathrm{HoFH}$, primary hypercholesterolemia or dyslipidemia (25-27). Evolocumab is an IgG2 antibody that binds to PCSK9 and inhibits its interplay with LDLRs (Table 1). Binding of evolocumab to PCSK9 decreases the amount of free PCSK9 and eventually enhances the available LDLRs for LDL in hepatocyte surface.

In the present meta-analysis of randomized controlled trials, we aimed to quantitatively evaluate the therapeutic effect of evolocumab, as a PCSK9 inhibitor on lipid profile in FH patients.

Table 1. Drug information

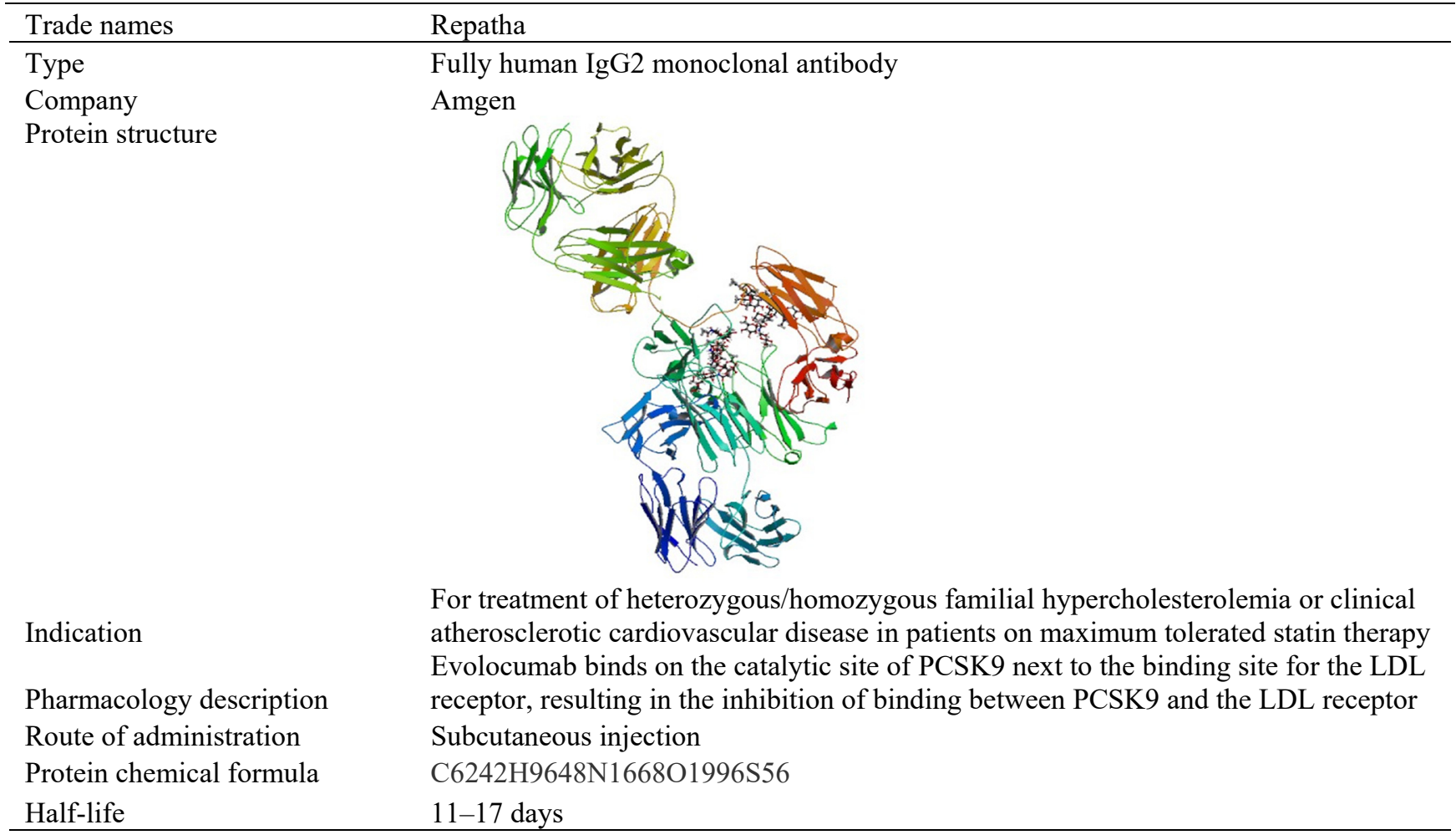

The provided information are adapted from http://www.drugbank.ca/drugs/DB09303

IgG2: Immunoglobulin G2, PCSK9: Proprotein convertase subtilisin/kexin type 9, LDL: Low-density lipoprotein, 


\section{METHODS}

\section{Data sources}

PubMed, Web of Science, and Scopus were searched for studies which investigated the efficacy of evolucomab in reducing lipid parameters. The search terms were "Evolocumab [Title/Abstract]) OR PCSK9 inhibitor [Title/Abstract])) AND Lipid profile (Total Cholesterol, LDL-C, HDL-C, VLDLC, Triglycerides) [Title/Abstract] AND Hypercholesterolemia [Title/Abstract]". An expert librarian was consulted for assistance in conducting a comprehensive search with appropriate search terms. We limited our search to studies written in English and there was no limitation for the years. At last, article reference lists underwent a review for additional applicable studies. In PubMed, our search was limited to clinical trials while in Scopus and Web of Science, all articles were reviewed. Studies were included if they met the following criteria: placebo-controlled, randomized, included outcomes of changes in lipid parameters in patients receiving evolocumab $420 \mathrm{mg}$ every 4 weeks versus placebo.

\section{Study selection}

The randomized controlled trials investigated the effect of evolocumab and its efficacy to ameliorate lipid profile in hypercholesterolemia patients receiving evolocumab $420 \mathrm{mg}$ every 4 weeks versus placebo, were considered. Two reviewers independently examined the title and abstract of each article to eliminate duplicates, reviews, case studies, and uncontrolled trials. Trials were excluded if they were not placebo-controlled or their outcomes did not possess the outcomes of interest. Percentage change of LDL-C was the primary outcome of interest for assessment of efficacy of evolocumab. The reviewers independently extracted data on patients' characteristics, therapeutic regimens, dosage, trial duration, and outcome measures. Disagreements, if any, were resolved by consensus.

\section{Assessment of trial quality}

The quality of evidence was determined using Grading of Recommendations Assessment, Development and Evaluation (GRADE) methodology (28). The GRADE system assesses risk of bias, imprecision, inconsistency, indirectness of study results, and publication bias across the body of evidence to derive an overall summary of the quality of evidence (Table 3).

\section{STATISTICAL ANALYSIS}

Data from selected studies were extracted in the form of $2 \times 2$ tables by study characteristics. Included studies were weighted by effect size and pooled. Data were analyzed using StatsDirect software version 3.0.190. Standardized effect size and 95\% confidence intervals $(95 \% \mathrm{CI})$ were calculated using Mulrow-Oxman (for fixed effects) and Der Simonian-Laird (for random effects) methods. The Cochran Q test and $\mathrm{I}^{2}$ inconsistency were used to test heterogeneity and $\mathrm{P}<0.05$ considered significant. When there is heterogeneity that cannot readily be explained or few included studies, the random effects model was used. Egger and Begg-Mazumdar tests were used to evaluate publication bias indicators in funnel plot.

\section{RESULTS}

A total of 8 eligible studies were included in the meta-analysis (Figure 1). Characteristics of included studies are shown in Table 2. An assessment of quality is shown in Table 3.

\section{Total Cholesterol (TC)}

\section{Effect of evolocumab in comparison to placebo therapy in TC in $\mathrm{FH}$ patients}

The summary for the standardized effect size of mean differences of \%change from baseline at the end of study for $\mathrm{TC}$ in $\mathrm{FH}$ patients " $\Delta \mathrm{TC}$ " for evolocumab therapy for six included studies comparing to placebo (29-34) was -35.08 with $95 \%$ $\mathrm{CI}=-38.34$ to $-31.81(\mathrm{P}<0.0001$, Figure $2 \mathrm{a})$. The Cochrane $\mathrm{Q}$ test for heterogeneity indicated that the studies are heterogeneous $(\mathrm{P}=0.003), \mathrm{I}^{2}$ (inconsistency) of $71.8 \%$ with $95 \% \mathrm{CI}=6.6 \%$ to $85.9 \%$ and could not be combined, thus the random effects for individual and summary of effect size for standardized mean differences was applied. For evaluation of publication bias Egger regression of normalized effect vs. precision for all included studies for " $\triangle \mathrm{TC}$ " in $\mathrm{FH}$ patients among evolocumab vs. placebo therapy was $-1.68(95 \% \mathrm{CI}=-6.69$ to 3.33, $\mathrm{P}=0.4$ ) and Begg-Mazumdar Kendall's test on the standardized effect vs. variance indicated tau $=$ $0.2, \mathrm{P}=0.47$ (Figure 2b). 

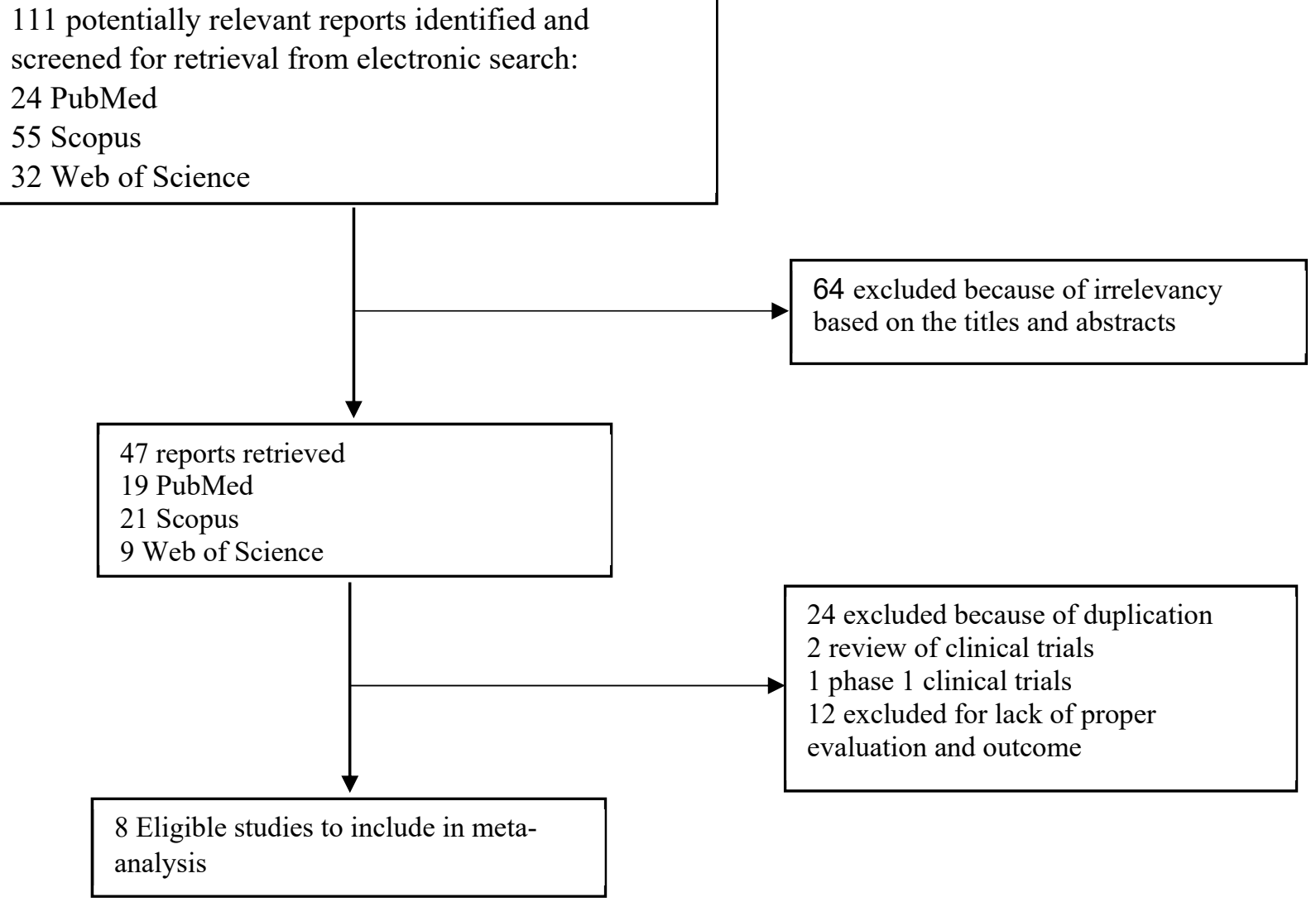

Figure 1. Study flow diagram

\section{Low-density lipoprotein Cholesterol (LDL-C) Effect of evolocumab in comparison to placebo therapy in LDL-C in $\mathrm{FH}$ patients}

The summary for the standardized effect size of mean differences of \%change from baseline at the end of the study for LDL-C in FH patients " $\Delta$ LDLC" for evolocumab therapy for eight included studies comparing to placebo (29-36) was -54.71 with $95 \%$ $\mathrm{CI}=-59.39$ to $-50.03(\mathrm{P}<0.0001$, Figure $2 \mathrm{c})$. The Cochrane $\mathrm{Q}$ test for heterogeneity indicated that the studies are heterogeneous $(\mathrm{P}<0.0001), \mathrm{I}^{2}$ (inconsistency) of $94.7 \%$ with $95 \% \mathrm{CI}=92.2 \%$ to $96.1 \%$ and could not be combined, thus the random effects for individual and summary of effect size for standardized mean differences was applied. For evaluation of publication bias Egger regression of normalized effect vs. precision for all included studies for " $\triangle \mathrm{LDL}-\mathrm{C}$ " in $\mathrm{FH}$ patients among evolocumab vs. placebo therapy was $-0.61(95 \% \mathrm{CI}=$ -6 to $4.77, \mathrm{P}=0.79$ ) and Begg-Mazumdar Kendall's test on the standardized effect vs. variance indicated tau $=0, P=0.91$ (Figure 2d).
High-density lipoprotein Cholesterol (HDL-C) Effect of evolocumab in comparison to placebo therapy in HDL-C in FH patients

The summary for the standardized effect size of mean differences of \%change from baseline at the end of the study for HDL-C in FH patients " $\Delta$ HDLC" for evolocumab therapy for eight included studies comparing to placebo (29-36) was 6.06 with $95 \%$ $\mathrm{CI}=4.7$ to $7.43(\mathrm{P}<0.0001$, Figure $3 \mathrm{a})$. The Cochrane $\mathrm{Q}$ test for heterogeneity indicated that the studies are not heterogeneous $(\mathrm{P}=0.25), \mathrm{I}^{2}$ (inconsistency) of $22.1 \%$ with $95 \% \mathrm{CI}=0 \%$ to $65.3 \%$ and could be combined, thus the fixed effects for individual and summary of effect size for standardized mean differences was applied. For evaluation of publication bias, Egger regression of normalized effect vs. precision for all included studies for " $\triangle \mathrm{HDL}-\mathrm{C}$ " in $\mathrm{FH}$ patients among evolocumab vs. placebo therapy was $0.78(95 \% \mathrm{CI}=$ -1.12 to 2.68, $\mathrm{P}=0.35$ ) and Begg-Mazumdar Kendall's test on the standardized effect vs. variance indicated tau $=0.21, \mathrm{P}=0.55$ (Figure $3 \mathrm{~b}$ ). 
Table 2. Characteristics of the 8 studies included in the meta-analysis

\begin{tabular}{|c|c|c|c|c|c|c|c|}
\hline Study & Year & Study population & No. & $\begin{array}{l}\text { Phase } \\
\text { of } \\
\text { trial }\end{array}$ & $\begin{array}{c}\text { Duration } \\
\text { of trial }\end{array}$ & Type of design & Ref \\
\hline MENDEL & 2012 & FH & 406 & 2 & 12 week & $\begin{array}{l}52 \text { Centers, randomized, } \\
\text { double-blind }\end{array}$ & (32) \\
\hline RUTHERFORD & 2012 & $\mathrm{HeFH}$ & 167 & 2 & 12 week & $\begin{array}{l}\text { Multicenter, double-blind, } \\
\text { randomized, placebo } \\
\text { controlled, dose-ranging }\end{array}$ & (33) \\
\hline OSLER & 2014 & $\begin{array}{l}\text { FH, Completed } \\
\text { Phase II parent } \\
\text { study }\end{array}$ & 1104 & 2 & 52 week & $\begin{array}{l}\text { Open-Label study of long } \\
\text { term evaluation, } \\
\text { randomized trial }\end{array}$ & (31) \\
\hline YUKAWA & 2014 & $\mathrm{FH}$ & 310 & 2 & 12 week & $\begin{array}{l}\text { Randomized, double- } \\
\text { blind, placebo-controlled }\end{array}$ & (30) \\
\hline MENDEL-2 & 2014 & FH & 614 & 3 & 12 week & $\begin{array}{l}\text { Compare biweekly and } \\
\text { monthly evolocumab with } \\
\text { placebo and ezetimibe }\end{array}$ & (35) \\
\hline RUTHERFORD-2 & 2014 & $\mathrm{HeFH}$ & 329 & 3 & 12 week & $\begin{array}{l}\text { Multicentre, randomised, } \\
\text { double-blind, placebo- } \\
\text { controlled trial }\end{array}$ & (36) \\
\hline TESLA Part B & 2014 & HoFH & 49 & 3 & 12 week & $\begin{array}{l}\text { Randomised, double- } \\
\text { blind, placebo-controlled }\end{array}$ & (34) \\
\hline DESCARTES & 2014 & FH & 901 & 3 & 52 week & $\begin{array}{l}\text { Randomized, double- } \\
\text { blind, placebo-controlled }\end{array}$ & (29) \\
\hline
\end{tabular}

\section{Effect size meta-analysis plot [random effects]}

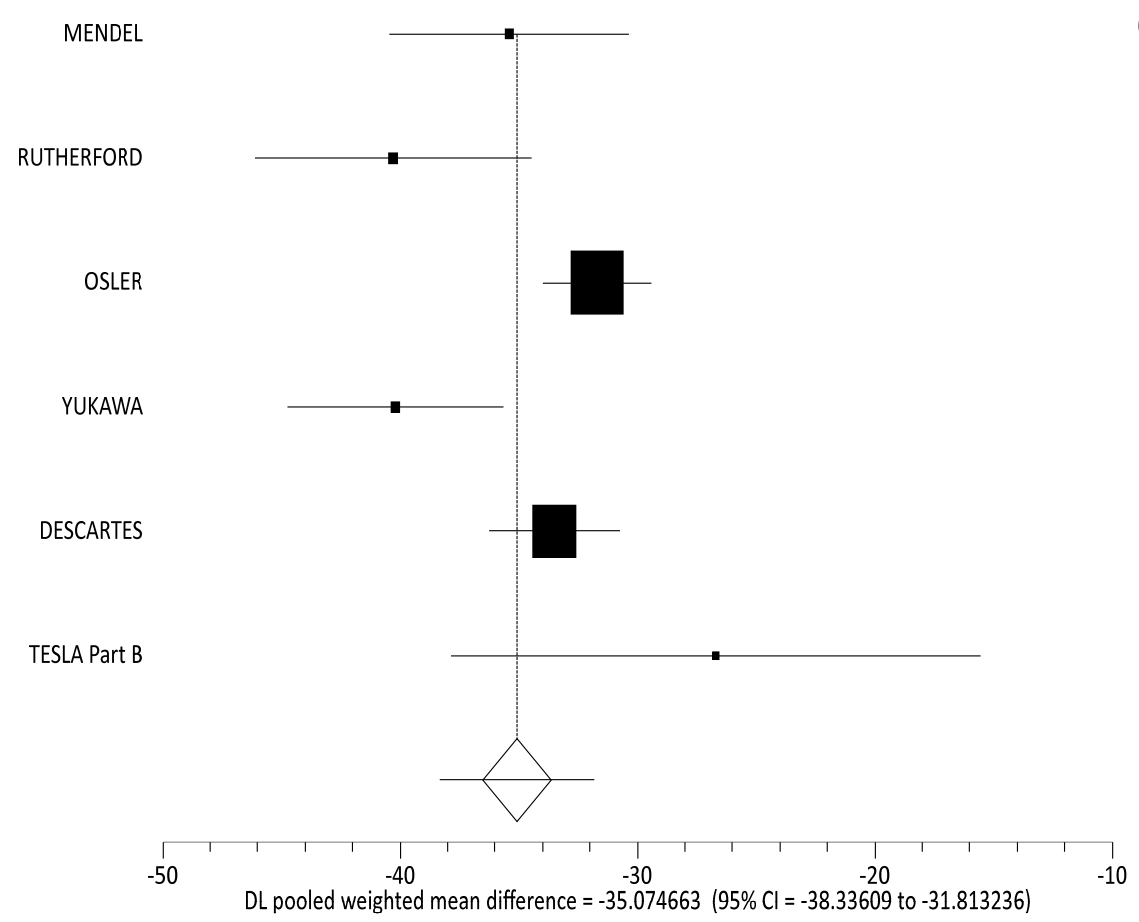

(a)

Figure 2 


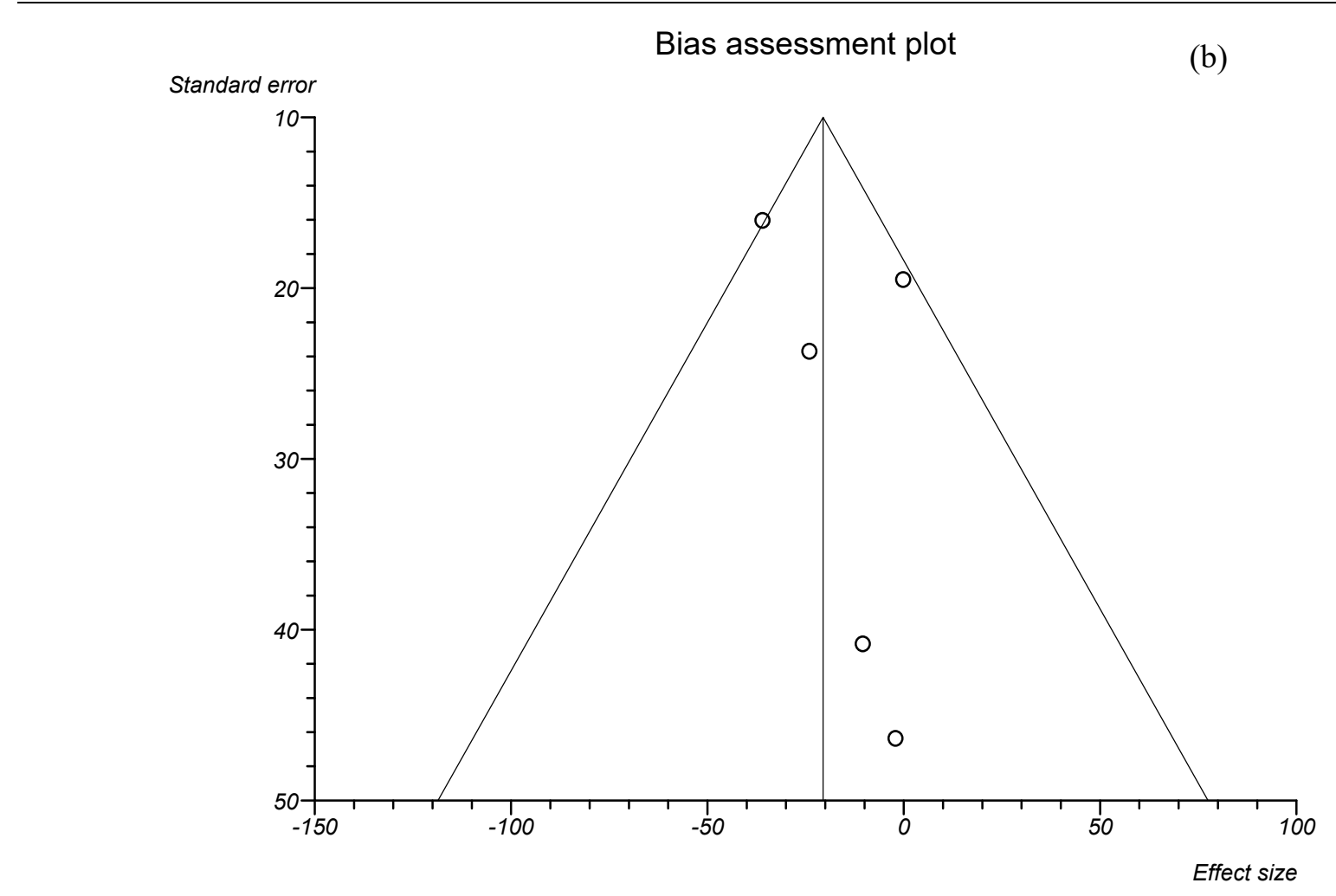

\section{Effect size meta-analysis plot [random effects]}

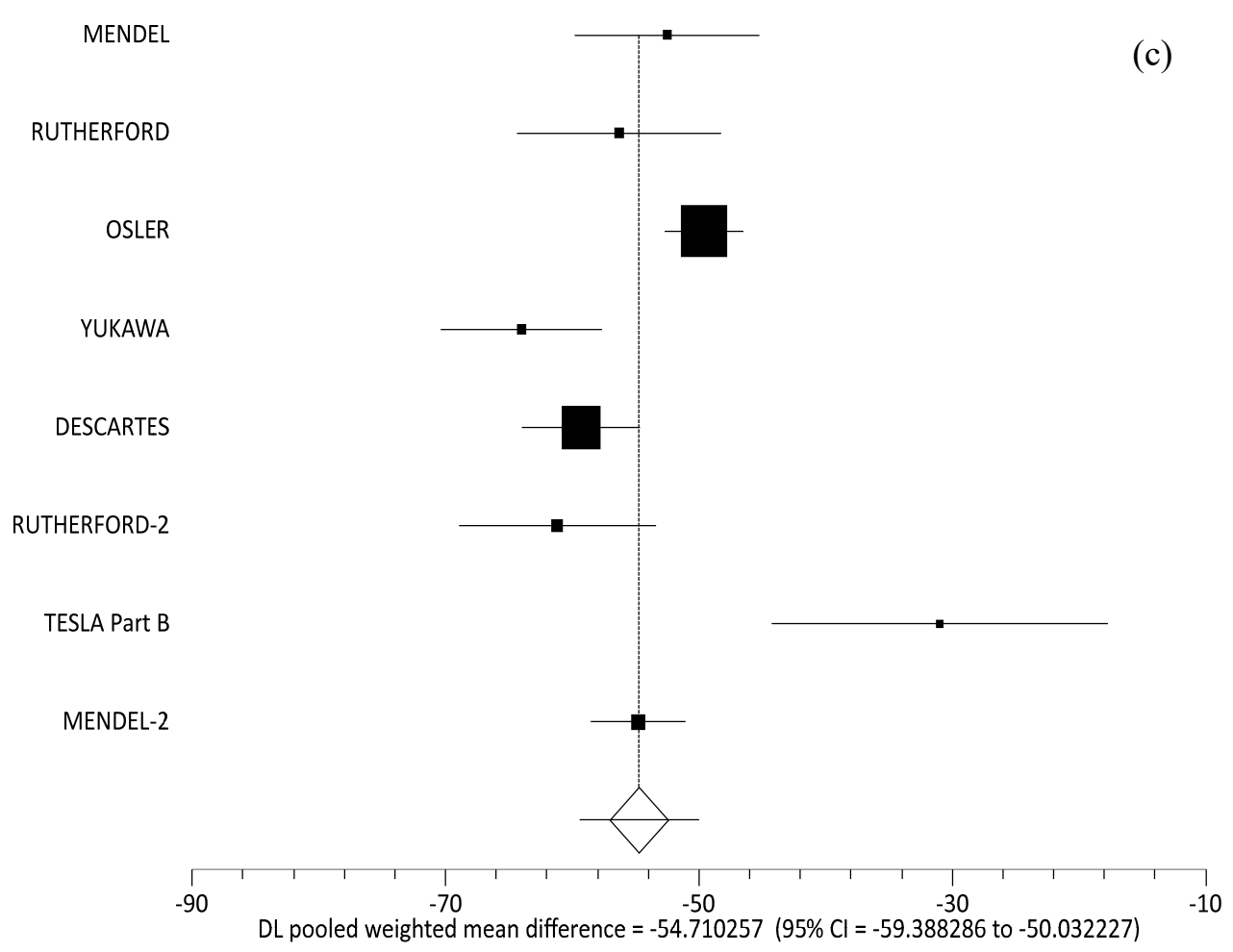

Figure 2 - Continued... 


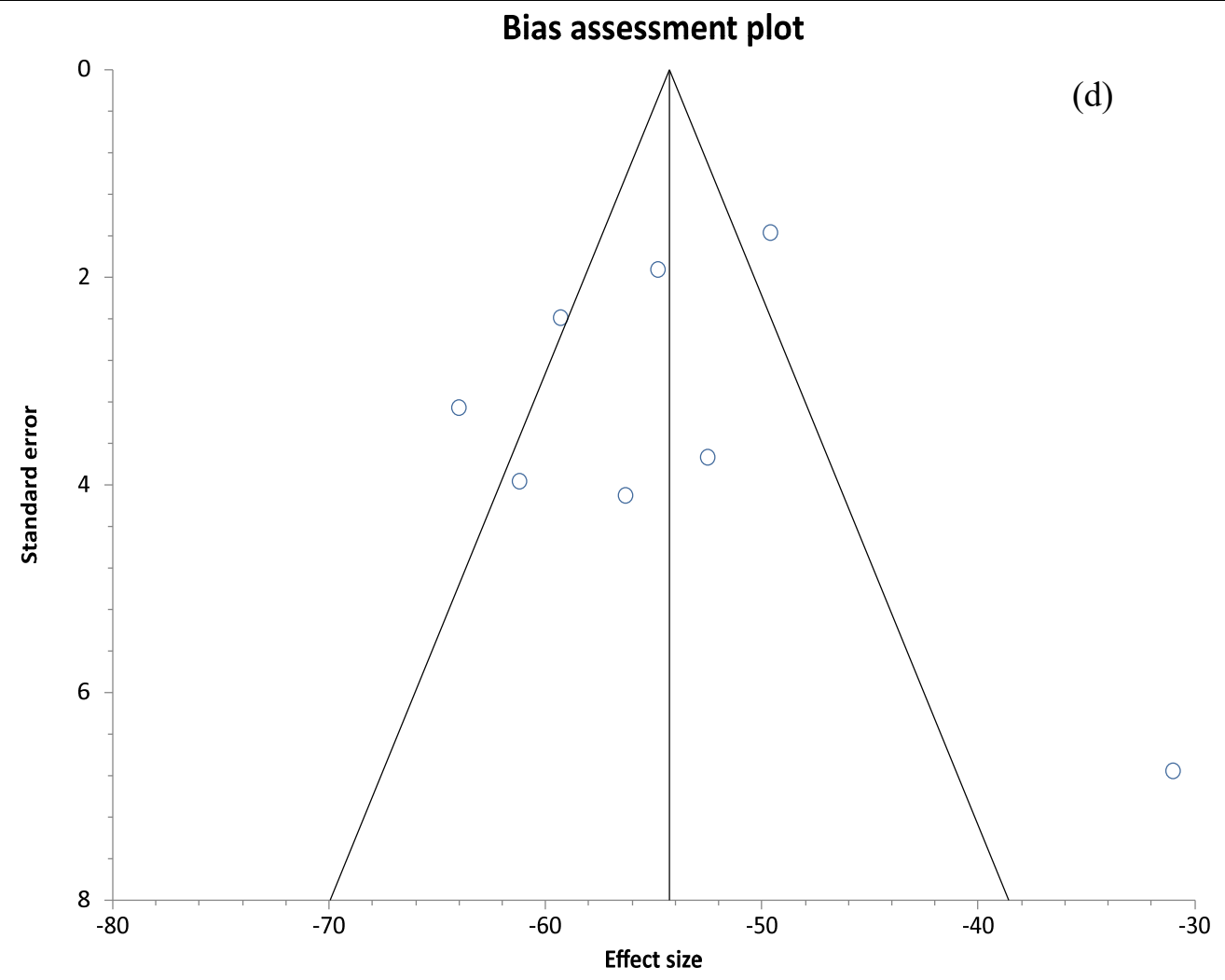

Figure 2. (a) Individual and pooled effect size for the outcome of " $\Delta \mathrm{TC}$ " in the studies considering evolocumab comparing to placebo therapy in $\mathrm{FH}$ patients (Heterogeneous Cochrane $\mathrm{Q}$ test for $\mathrm{P}=0.003$ and $\mathrm{I}^{2}=71.8 \%$ with $95 \% \mathrm{CI}$ of $6.6 \%$ to $85.9 \%$ ). (b) Publication bias indicators for the outcome of " $\Delta \mathrm{TC}$ " in the studies considering evolocumab comparing to placebo therapy in FH patients. (c) Individual and pooled effect size for the outcome of " $\Delta \mathrm{LDL}-\mathrm{C}$ " in the studies considering evolocumab comparing to placebo therapy in $\mathrm{FH}$ patients (Heterogeneous Cochrane Q test for $\mathrm{P}<0.0001$ and $\mathrm{I}^{2}=94.7 \%$ with $95 \%$ CI of $92.2 \%$ to $96.1 \%$ ). (d) Publication bias indicators for the outcome of " $\Delta$ LDL-C" in the studies considering evolocumab comparing to placebo therapy in FH patients.

\section{Very Low-density Lipoprotein Cholesterol (VLDL-C) \\ Effect of evolocumab in comparison to placebo therapy in VLDL-C in FH patients}

The summary for the standardized effect size of mean differences of $\%$ change from baseline at the end of the study for VLDL-C in FH patients " $\triangle$ VLDL-C" for evolocumab therapy for five included studies comparing to placebo $(29,32-35)$ was -28.37 with $95 \% \mathrm{CI}=-36.7$ to $-20.04(\mathrm{P}<0.0001$, Figure $3 \mathrm{c})$. The Cochrane $\mathrm{Q}$ test for heterogeneity indicated that the studies are not heterogeneous $(\mathrm{P}=$ 0.82 ), $\mathrm{I}^{2}$ (inconsistency) of $0 \%$ with $95 \% \mathrm{CI}=0 \%$ to $64.1 \%$ and could be combined, thus the fixed effects for individual and summary of effect size for standardized mean differences was applied. For evaluation of publication bias Egger regression of normalized effect vs. precision for all included studies for " $\triangle$ VLDL-C" in FH patients among evolocumab vs. placebo therapy was $0.07(95 \% \mathrm{CI}=$
-2.16 to $2.29, \mathrm{P}=0.93$ ) and Begg-Mazumdar Kendall's test on the standardized effect vs. variance indicated tau $=0, \mathrm{P}=0.82$ (Figure $3 \mathrm{~d}$ ).

\section{Ratio of TC to HDL-C}

Effect of evolocumab in comparison to placebo therapy in Ratio of TC to HDL-C in FH patients

The summary for the standardized effect size of mean differences of \% change from baseline at the end of the study for the Ratio of TC to HDL-C in FH patients " $\Delta$ Ratio of TC to HDL-C" for evolocumab therapy for seven included studies comparing to placebo $(29-34,36)$ was -39.14 with $95 \% \mathrm{CI}=-43.34$ to $-34.95(\mathrm{P}<0.0001$, Figure $4 \mathrm{a})$. The Cochrane $\mathrm{Q}$ test for heterogeneity indicated that the studies are heterogeneous $(\mathrm{P}=0.0002), \mathrm{I}^{2}$ (inconsistency) of $77 \%$ with $95 \% \mathrm{CI}=41 \%$ to $87.4 \%$ and could not be combined, thus the random effects for individual and summary of effect size for standardized mean differences was applied. For evaluation of 
publication bias Egger regression of normalized effect vs. precision for all included studies for " $\triangle$ Ratio of TC to HDL-C" in FH patients among evolocumab vs. placebo therapy was $-1.99(95 \% \mathrm{CI}=$
-6.41 to 2.42, $\mathrm{P}=0.3$ ) and Begg-Mazumdar Kendall's test on the standardized effect vs. variance indicated tau $=-0.05, \mathrm{P}=0.77$ (Figure $4 \mathrm{~b}$ ).

\section{Effect size meta-analysis plot [fixed effects]}

(a)

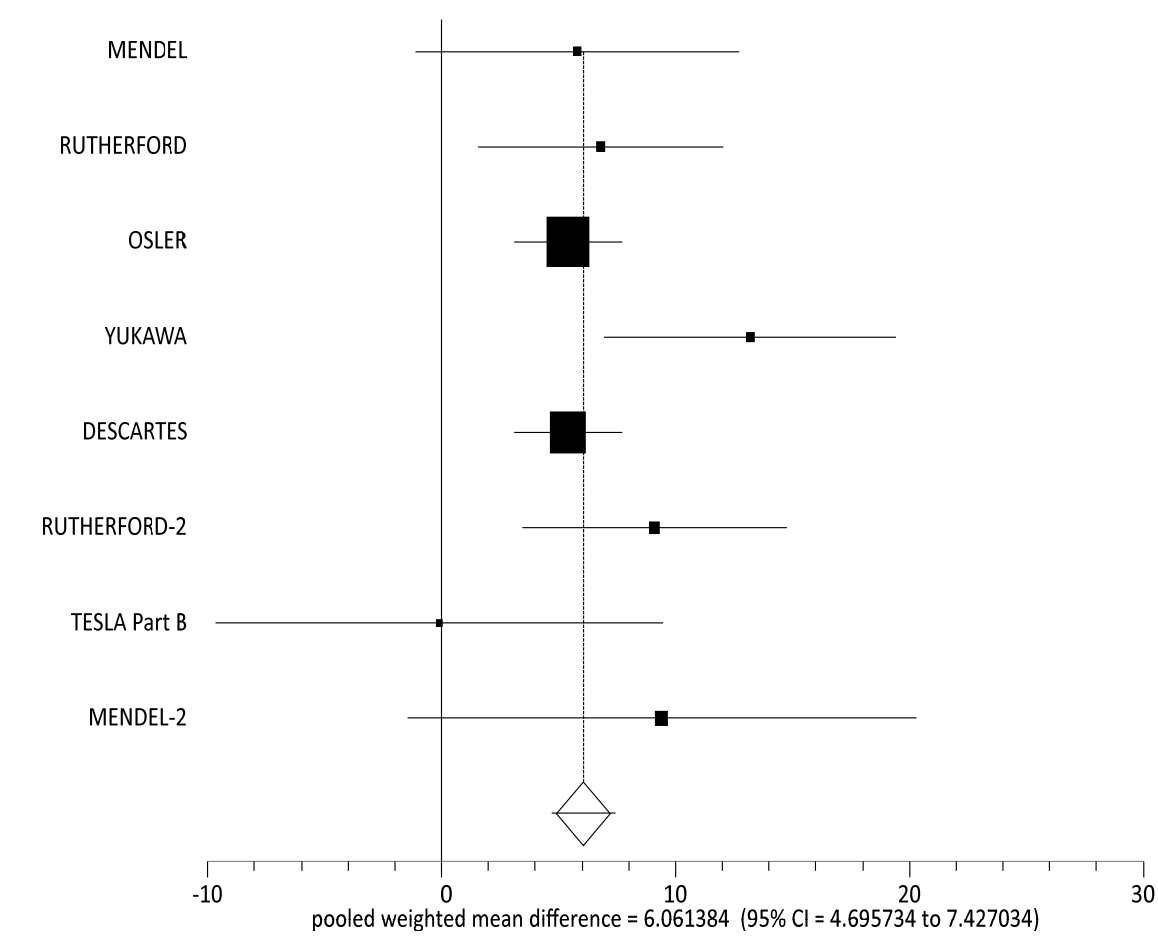

Bias assessment plot

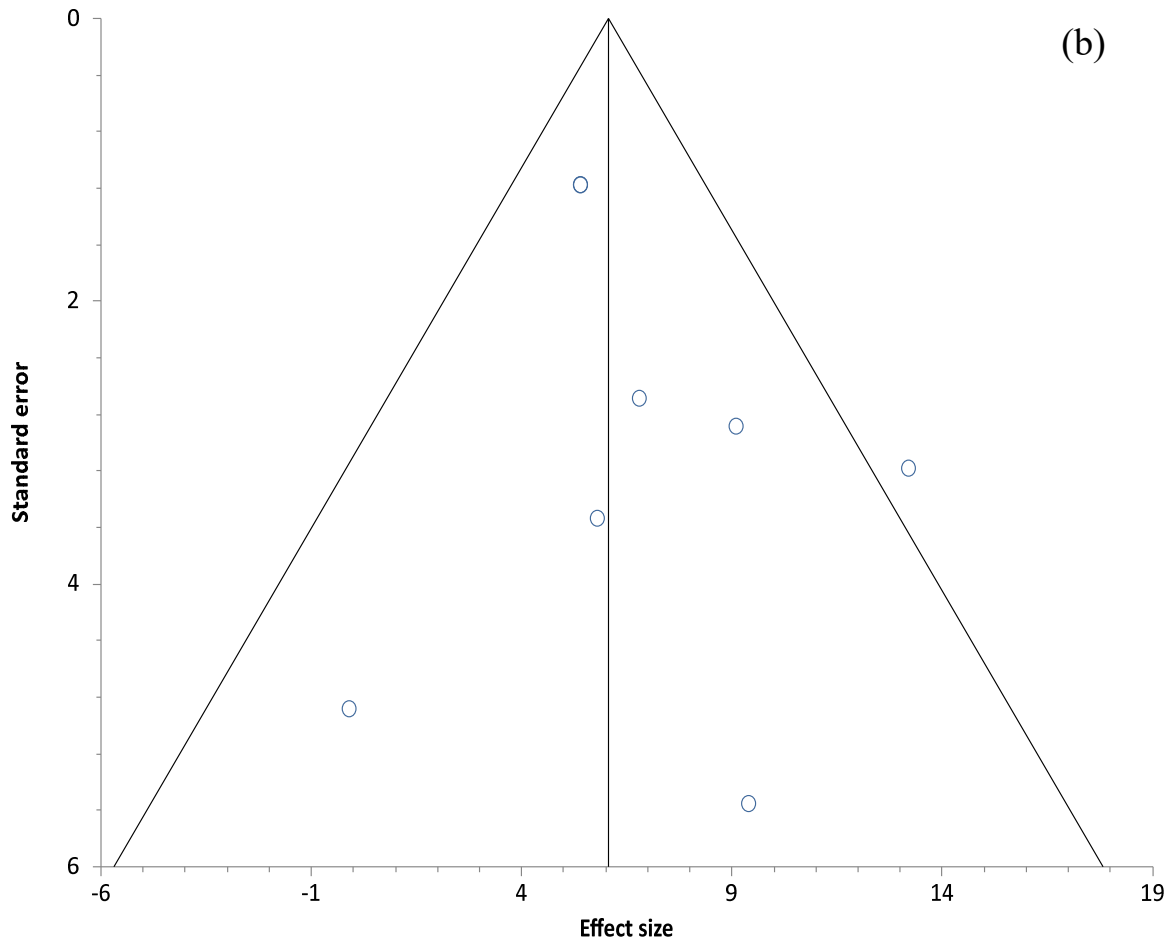

Figure 3 


\section{Effect size meta-analysis plot [fixed effects]}
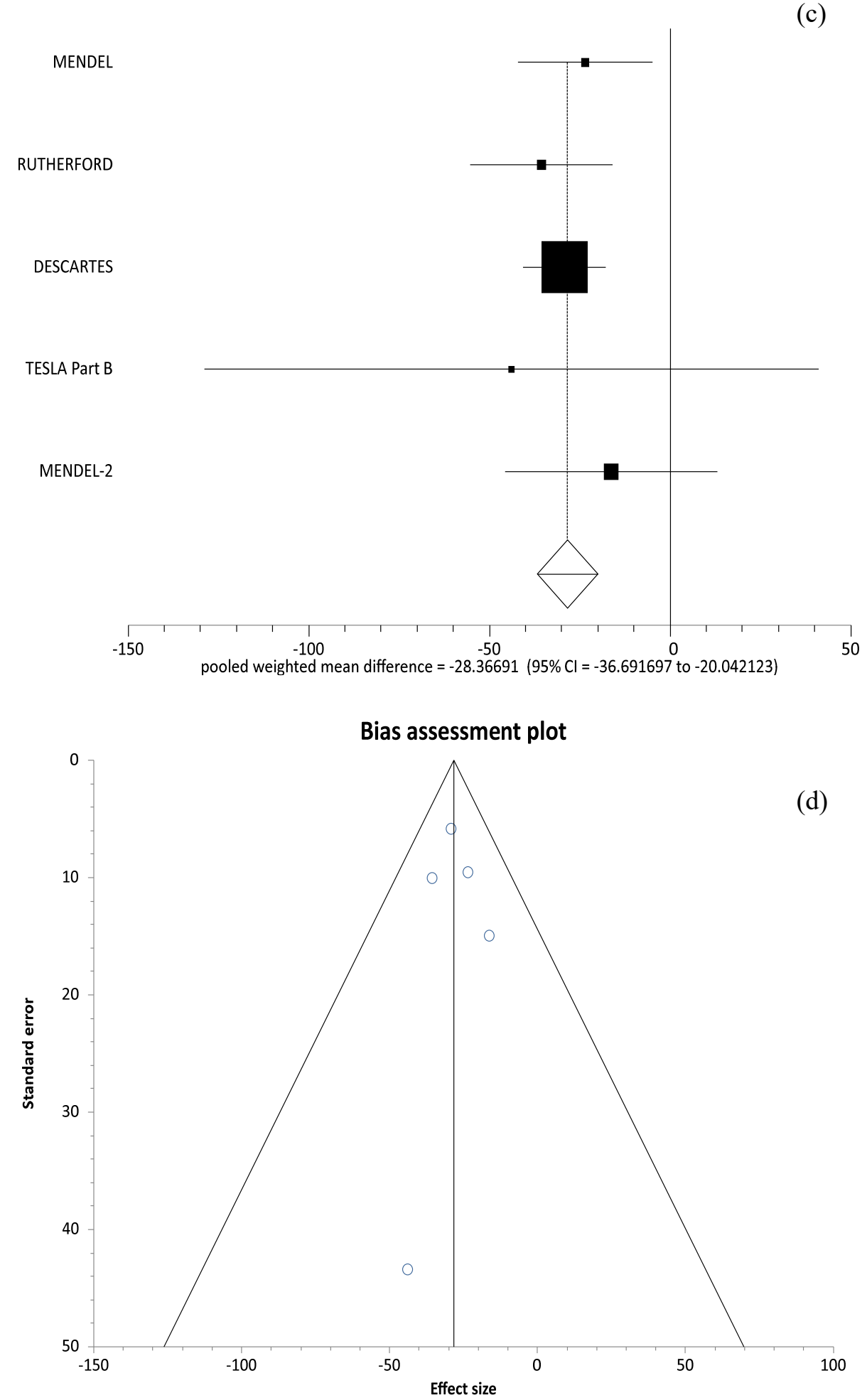

Figure 3. (a) Individual and pooled effect size for the outcome of " $\triangle \mathrm{HDL}-\mathrm{C}$ " in the studies considering evolocumab comparing to placebo therapy in FH patients (Heterogeneous Cochrane $\mathrm{Q}$ test for $\mathrm{P}=0.25$ and $\mathrm{I}^{2}=22.1 \%$ with $95 \% \mathrm{CI}$ of $0 \%$ to $65.3 \%$ ). (b) Publication bias indicators for the outcome of " $\Delta$ HDL-C" in the studies considering evolocumab comparing to placebo therapy in FH patients. (c) Individual and pooled effect size for the outcome of " $\triangle$ VLDL-C" in the studies considering evolocumab comparing to placebo therapy in FH patients (Heterogeneous Cochrane $\mathrm{Q}$ test for $\mathrm{P}=0.82$ and $\mathrm{I}^{2}=$ $0 \%$ with $95 \%$ CI of $0 \%$ to $64.1 \%$ ). (d) Publication bias indicators for the outcome of " $\triangle$ VLDL-C" in the studies considering evolocumab comparing to placebo therapy in $\mathrm{FH}$ patients. 


\section{Triglycerides (TG)}

\section{Effect of evolocumab in comparison to placebo} therapy in TG in FH patients

The summary for the standardized effect size of mean differences of \%change from baseline at the end of the study for TG in FH patients " $\Delta \mathrm{TG}$ " for evolocumab therapy for seven included studies compared to placebo $(29,30,32-36)$ was -12.11 with $95 \% \mathrm{CI}=-16.05$ to $-8.16(\mathrm{P}<0.0001$, Figure $4 \mathrm{c})$. The Cochrane $\mathrm{Q}$ test for heterogeneity indicated that the studies are not heterogeneous $(\mathrm{P}=0.29), \mathrm{I}^{2}$ (inconsistency) of $18.9 \%$ with $95 \% \mathrm{CI}=0 \%$ to $65.9 \%$ and could be combined, thus the fixed effects for individual and summary of effect size for standardized mean differences was applied. For evaluation of publication bias Egger regression of normalized effect vs. precision for all included studies for " $\Delta \mathrm{TG}$ " in $\mathrm{FH}$ patients among evolocumab vs. placebo therapy was $0.1(95 \% \mathrm{CI}=-2.69$ to 2.88 , $\mathrm{P}=0.93$ ) and Begg-Mazumdar Kendall's test on the standardized effect vs. variance indicated tau $=0.14$, $\mathrm{P}=0.77$ (Figure $4 \mathrm{~d}$ ).

\section{DISCUSSION}

This is the first time that a meta-analysis has been carried out to investigate the efficacy of evolocumab, as a lipid lowering agent in $\mathrm{FH}$ patients. In the present meta-analysis, 8 randomized controlled trials consisting of 3880 patients were included. Our metaanalysis shows that evolocumab at the dosage of 420 mg monthly could decrease $54.71 \%$ of LDL-C, $35.08 \%$ of TC, $28.37 \%$ of VLDL-C, $39.14 \%$ of ratio of TC to HDL-C, $12.11 \%$ of TG, and increased $6.06 \%$ of HDL-C from baseline compared to placebo at the end of study in $\mathrm{FH}$ patients.

Although plenty of medications have been used by the aim of managing lipid profile and reducing the risk of cardiovascular diseases in $\mathrm{FH}$ patients, still it is not under control (37). Statins, which are the most efficient agents for alleviating LDL-C level, many of the patients treating with statins are incapable to tolerate them mainly because of muscle-related side effects or higher dose is required to attain the target LDL-C (38). Nevertheless, statin intolerant patients have a need for more effective LDL-C lowering therapies

\section{Effect size meta-analysis plot [random effects]}

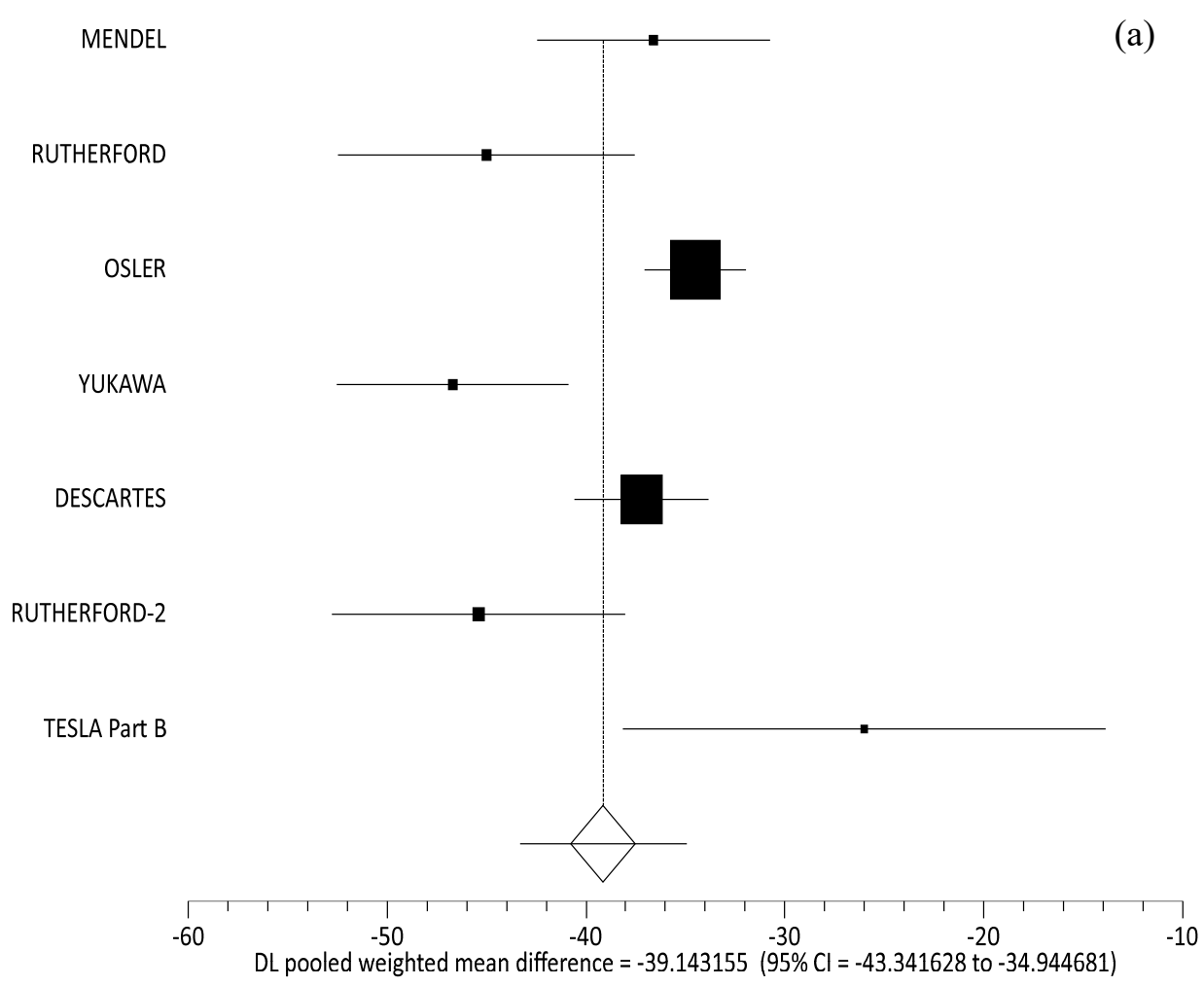

Figure 4 


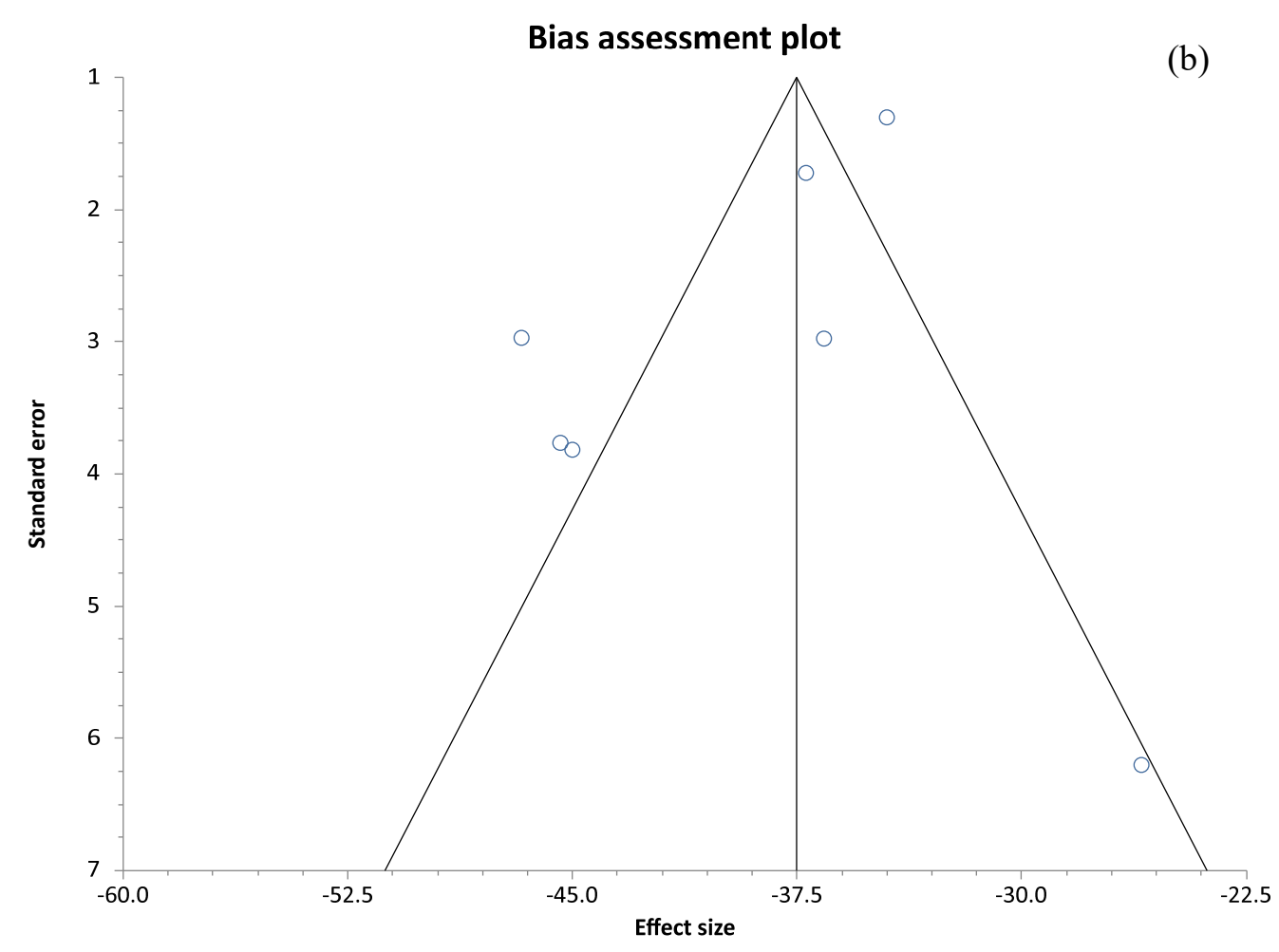

Effect size meta-analysis plot [fixed effects]

(c)

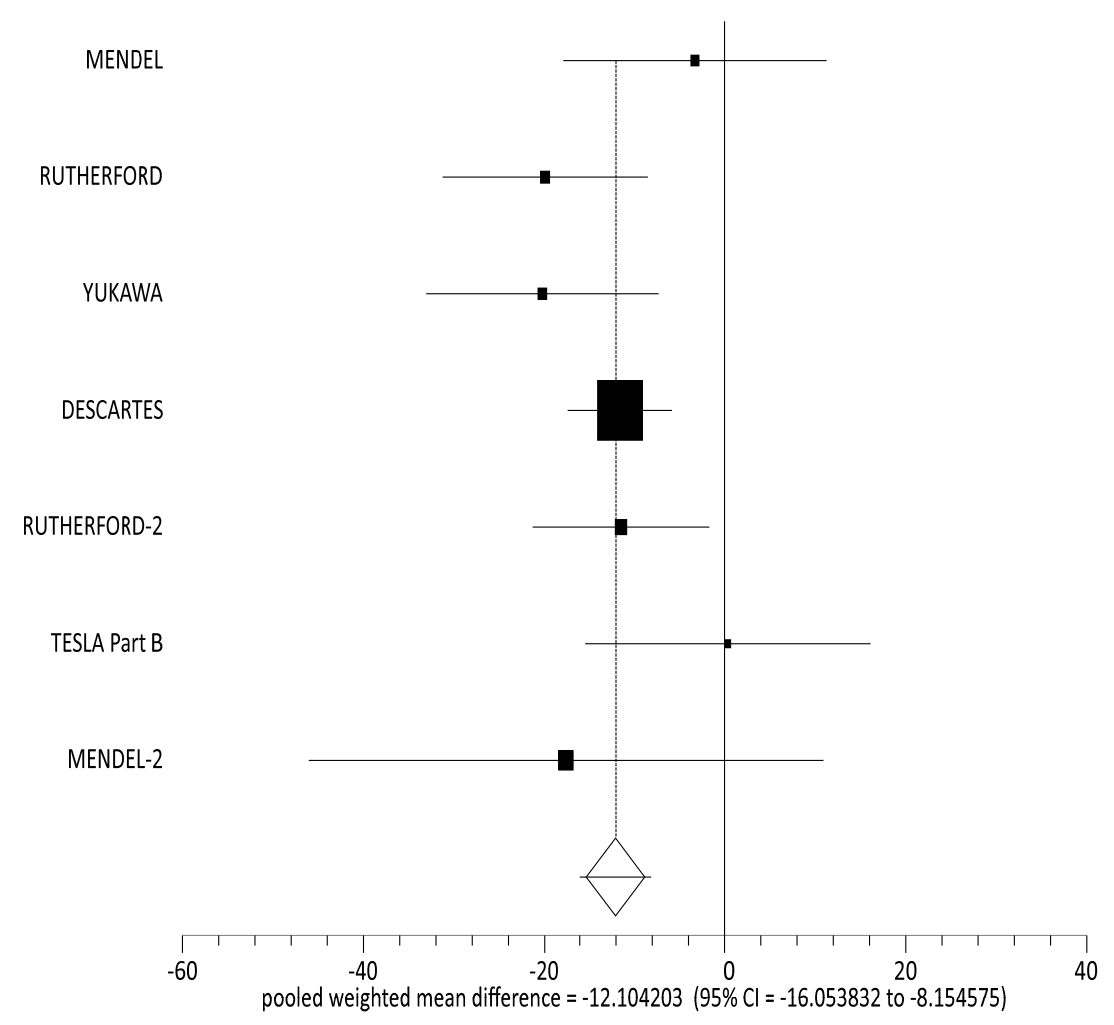

Figure 4 - Continued... 


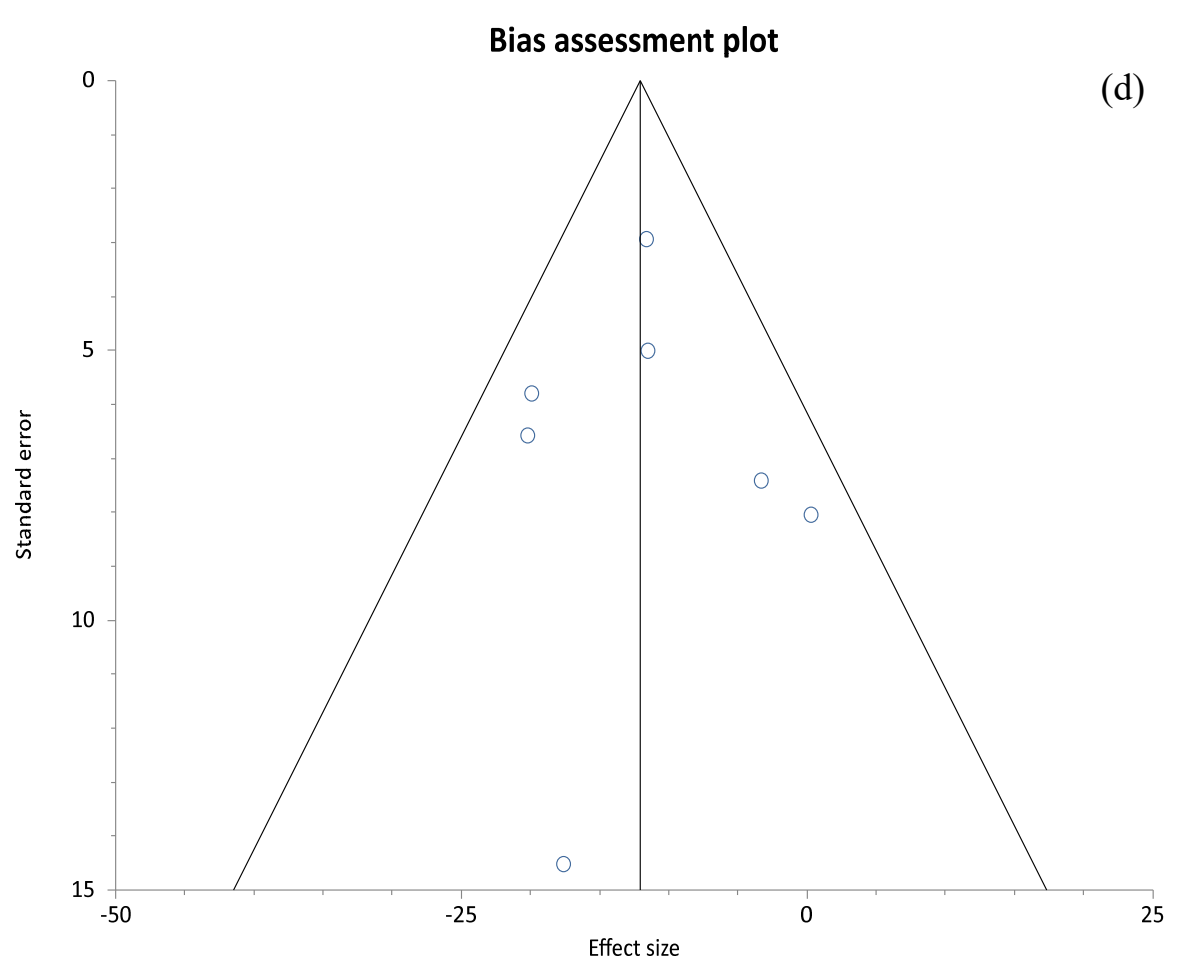

Figure 4. (a) Individual and pooled effect size for the outcome of " $\triangle$ Ratio of TC to HDL-C" in the studies considering evolocumab comparing to placebo therapy in FH patients (Heterogeneous Cochrane Q test for $\mathrm{P}=$ 0.0002 and $\mathrm{I}^{2}=77 \%$ with $95 \% \mathrm{CI}$ of $41 \%$ to $87.4 \%$ ). (b) Publication bias indicators for the outcome of " $\Delta$ Ratio of TC to HDL-C" in the studies considering evolocumab comparing to placebo therapy in FH patients. (c) Individual and pooled effect size for the outcome of " $\Delta \mathrm{TG}$ " in the studies considering evolocumab comparing to placebo therapy in FH patients (Heterogeneous Cochrane Q test for $\mathrm{P}=0.29$ and $\mathrm{I}^{2}=18.9 \%$ with $95 \% \mathrm{CI}$ of $0 \%$ to $65.9 \%$ ). (d) Publication bias indicators for the outcome of " $\Delta \mathrm{TG}$ " in the studies considering evolocumab comparing to placebo therapy in FH patients.

Different doses of evolocumab monotherapy comprising of $70 \mathrm{mg}, 105 \mathrm{mg}$, or $140 \mathrm{mg}$ every 2 weeks; and $280 \mathrm{mg}, 350 \mathrm{mg}$, or $420 \mathrm{mg}$ every 4 weeks were scheduled in studies. Through the literatures, comparing the two high doses $(140 \mathrm{mg}$ every 2 weeks; and $420 \mathrm{mg}$ every 4 weeks) illustrated no difference in LDL-C reduction (32). Through these, we analyzed data for evolocumab $420 \mathrm{mg}$ every 4 weeks due to its more compliance and less injection frequency.

We have shown that evolocumab therapy significantly decreased $\mathrm{TC}$ in $\mathrm{FH}$ patients. The RUTHERFORD study (33) showed more reduction of TC in comparison to other studies. The included patients were HeFH with statin therapy. Evolocumab therapy in the TESLA Part B (34) study had least effect on TC probably because of HoFH-included patients which is the severe form of FH and likely less responsive to evolocumab. These results prove that evolocumab is more effective in $\mathrm{HeFH}$ rather than HoFH. To confirm this, the correlation between response to evolocumab and underlying genetic cause of FH has been announced (34). However, another study reported that response to evolocumab is not related to the underlying genetic background (36).

Among these studies, YUKAWA (30) with the Japanese FH patients had more reduction in LDL-C. Maybe that is why in Japan, lower doses and less potent of statins are used and fewer included patients in YUKAWA (30) were on high-intensity statin therapy. Also, it has been shown that evolocumab therapy in patients receiving non-intensive statin therapy had greater reduction of LDL-C compared to group receiving intensive statin therapy. Considering this fact, it could be concluded that evolocumab decreases LDL-C more in non-intensive statin therapy rather than high-intensity statin therapy. Evolocumab in TESLA Part B (34) was less effective to reduce LDL-C, justifying that evolocumab does 
not have the same effect on HoFH. However, in the group of genetically authenticated homozygous patients with mutations in LDLRs, there was a variation in LDL-C reduction, proposing that other factors are involved in lowering of LDL-C.

On the other hand, evolocumab therapy increased HDL-C in HF patients. Improvement in HDL-C concentrations was speculated as reduced ability of cholesterol to be transferred from HDL-C to LDL-C, rather than a direct effect on HDL-C production (39). In Japanese $\mathrm{FH}$ patients, more increment of HDL-C was reported (30). Maybe this refers to their better responsiveness to evolocumab due to non-intensive statin therapy background.

Combination therapy of evolocumab and statins in $\mathrm{FH}$ patients helped most of the patients to achieve the goal LDL-C concentration (39). Interestingly another study reported that patients receiving evolocumab with moderate intensity statins had a slightly greater reduction in PCSK9 compared to those received high-intensity statins, representing the upregulative effect of statins on PCSK9 (40). Furthermore, not only the baseline PCSK9 levels were higher in patients receiving atorvastatin plus evolocumab, but there was also a rapid increase in PCSK9 levels 4 weeks after administration of this combination (29). Due to this phenomenon, it seems that a combination of non-statin medication with evolocumab could be more efficient. Besides, it has not been shown which statin in combination with evolocumab is more beneficial, propelling the design of future studies. Also, addition of ezetimibe to evolocumab was shown to be more efficient compared to evolocumab alone $(38,41)$.

In a large longer-term evaluation of evolocumab with heterogeneous population which was recruited from 4 phase 2 parent studies of $\mathrm{FH}$ patients (31), showed that patients who were receiving evolocumab in their parent study and received it in this study too, had a continuing reduction of LDL-C, implying that no pharmacoresistance was detected during this period. Discontinuation of evolocumab therapy for patients who were using it in parent study and interrupted it in this study, led to rapid return of LDL-C level, representing that evolocumab therapy is somehow a "treatment" rather than "cure".

In conclusion, our meta-analysis shows that evolocumab as a PCSK9 inhibitor, could ameliorate lipid profile in FH patients. Evolocumab decreased not only LDL-C, but also other lipoprotein markers and increased HDL-C significantly. These findings indicate that evolocumab, with a notable efficacy and novel approach could be a hopeful agent for challenging patients, such as statin intolerance or patients who fail to attain the target goal of LDL-C despite consumption of maximum doses of statins. However statistical heterogeneity exists, thus random effects have been applied in the current meta-analysis. To provide valid results about its efficacy, long-term adverse effects and assessment of its cost-benefit issues, further studies are required.

\section{ACKNOWLEDGMENTS}

The authors thank the support of National Institute for Medical Research Development (NIMAD).

\section{AUTHORS' CONTRIBUTION}

Data were collected by SME and MG. SN did metaanalysis and completed methods and results. The manuscript was drafted by SME, SN, MG and edited by MA. The idea of the study was from SN and MA. MA supervised whole study. All authors read and approved the final manuscript.

\section{COMPETING INTEREST}

The authors declare no conflict of interest.

\section{REFERENCES}

1. Austin MA, Hutter CM, Zimmern RL, Humphries SE. Genetic causes of monogenic heterozygous familial hypercholesterolemia: a HuGE prevalence review. American journal of epidemiology. 2004;160(5):407-20. DOI: 10.1093/aje/kwh236

2. Usifo E, Leigh SE, Whittall RA, Lench N, Taylor A, Yeats C, et al. Low-density lipoprotein receptor gene familial hypercholesterolemia variant database: update and pathological assessment. Annals of human genetics. 2012;76(5):387-401. DOI: 10.1111/j.1469-1809.2012.00724.x.

3. Langer T, Strober W, Levy RI. The metabolism of low density lipoprotein in familial type II hyperlipoproteinemia. Journal of Clinical Investigation. 1972;51(6):1528. DOI: 10.1172/JCI106949

4. Faiz F, Hooper AJ, van Bockxmeer FM. Molecular pathology of familial hypercholesterolemia, related dyslipidemias and therapies beyond the statins. Critical reviews in clinical laboratory sciences. 2012;49(1):1-17.

DOI: 10.3109/10408363.2011.64694

5. Soutar AK, Naoumova RP. Mechanisms of disease: genetic causes of familial hypercholesterolemia. 
Nature clinical practice Cardiovascular medicine. 2007;4(4):214-25. DOI: 10.1038/ncpcardio0836

6. Artenstein AW, Opal SM. Proprotein convertases in health and disease. The New England Journal of Medicine. 2011;365(26):2507-18. DOI: 10.1056/NEJMra1106700

7. Benjannet S, Rhainds D, Essalmani R, Mayne J, Wickham L, Jin W, et al. NARC-1/PCSK9 and its natural mutants zymogen cleavage and effects on the low density lipoprotein (LDL) receptor and LDL cholesterol. Journal of Biological Chemistry. 2004;279(47):48865-75.

DOI: 10.1074/jbc.M409699200

8. Kosenko T, Golder M, Leblond G, Weng W, Lagace TA. Low density lipoprotein binds to proprotein convertase subtilisin/kexin type-9 (PCSK9) in human plasma and inhibits PCSK9-mediated low density lipoprotein receptor degradation. Journal of Biological Chemistry. 2013;288(12):8279-88. DOI: 10.1074/jbc.M112.421370

9. Nassoury N, Blasiole DA, Tebon Oler A, Benjannet $\mathrm{S}$, Hamelin J, Poupon V, et al. The cellular trafficking of the secretory proprotein convertase PCSK9 and its dependence on the LDLR. Traffic. 2007;8(6):718-32. DOI: $10.1111 / \mathrm{j} .1600-0854.2007 .00562 . x$

10. Qian YW, Schmidt RJ, Zhang Y, Chu S, Lin A, Wang $\mathrm{H}$, et al. Secreted PCSK9 downregulates low density lipoprotein receptor through receptor-mediated endocytosis. The Journal of Lipid Research. 2007;48(7):1488-98. DOI: 10.1194/jlr.M700071JLR200

11. Lambert G, Sjouke B, Choque B, Kastelein JJ, Hovingh GK. The PCSK9 decade Thematic Review Series: New Lipid and Lipoprotein Targets for the Treatment of Cardiometabolic Diseases. Journal of lipid research. 2012;53(12):2515-24. DOI: 10.1194/jlr.R026658

12. Seidah NG, Awan Z, Chrétien M, Mbikay M. PCSK9 A Key Modulator of Cardiovascular Health. Circulation research. 2014;114(6):1022-36. DOI: 10.1161/CIRCRESAHA.114.301621

13. Zhang D-W, Garuti R, Tang W-J, Cohen JC, Hobbs HH. Structural requirements for PCSK9-mediated degradation of the low-density lipoprotein receptor. Proceedings of the National Academy of Sciences. 2008;105(35):13045-50.

DOI: 10.1073/pnas.0806312105

14. Cohen JC, Boerwinkle E, Mosley Jr TH, Hobbs HH. Sequence variations in PCSK9, low LDL, and protection against coronary heart disease. New England Journal of Medicine. 2006;354(12):1264-72. DOI: 10.1056/NEJMoa054013

15. Lose JM, Dorsch MP, Bleske BE. Evaluation of Proprotein Convertase Subtilisin/Kexin Type 9: Focus on Potential Clinical and Therapeutic Implications for Low-Density Lipoprotein Cholesterol Lowering. Pharmacotherapy: The
Journal of Human Pharmacology and Drug Therapy. 2013;33(4):447-60. DOI: 10.1002/phar.1222

16. Desai NR, Sabatine MS. PCSK9 inhibition in patients with hypercholesterolemia. Trends in cardiovascular medicine. 2015;25(7):567-74. DOI: 10.1016/j.tcm.2015.01.009

17. Awan Z, Seidah NG, MacFadyen JG, Benjannet S, Chasman DI, Ridker PM, et al. Rosuvastatin, proprotein convertase subtilisin/kexin type 9 concentrations, and LDL cholesterol response: the JUPITER trial. Clinical Chemistry. 2012;58(1):1839. DOI: $10.1373 /$ clinchem.2011.172932

18. Careskey HE, Davis RA, Alborn WE, Troutt JS, Cao G, Konrad RJ. Atorvastatin increases human serum levels of proprotein convertase subtilisin/kexin type 9. The Journal of Lipid Research. 2008;49(2):394-8. DOI: 10.1194/jlr.M700437-JLR200

19. Davignon J, Dubuc G. Statins and ezetimibe modulate plasma proprotein convertase subtilisin kexin-9 (PCSK9) levels. Transactions of the American Clinical and Climatological Association. 2009;120:163.

20. Persson L, Cao G, Ståhle L, Sjöberg BG, Troutt JS, Konrad RJ, et al. Circulating proprotein convertase subtilisin kexin type 9 has a diurnal rhythm synchronous with cholesterol synthesis and is reduced by fasting in humans. Arteriosclerosis, thrombosis, and vascular biology. 2010;30(12):266672. DOI: 10.1161/ATVBAHA.110.214130

21. Welder G, Zineh I, Pacanowski MA, Troutt JS, Cao G, Konrad RJ. High-dose atorvastatin causes a rapid sustained increase in human serum PCSK9 and disrupts its correlation with LDL cholesterol. Journal of lipid research. 2010;51(9):2714-21. DOI: 10.1194/jlr.M008144

22. Rashid S, Curtis DE, Garuti R, Anderson NN, Bashmakov Y, Ho Y, et al. Decreased plasma cholesterol and hypersensitivity to statins in mice lacking Pcsk9. Proceedings of the National Academy of Sciences of the United States of America. 2005;102(15):5374-9.

DOI: 10.1073/pnas.0501652102

23. Urban D, Pöss J, Böhm M, Laufs U. Targeting the proprotein convertase subtilisin/kexin type 9 for the treatment of dyslipidemia and atherosclerosis. Journal of the American College of Cardiology. 2013;62(16):1401-8.

DOI: 10.1016/j.jacc.2013.07.056

24. Marais AD, Kim JB, Wasserman SM, Lambert G. PCSK9 inhibition in LDL cholesterol reduction: genetics and therapeutic implications of very low plasma lipoprotein levels. Pharmacology \& Therapeutics. 2015;145:58-66. DOI: 10.1016/j.pharmthera.2014.07.004

25. European Medicines Agency. Repatha (evolocumab): EU summary of product characteristics. 2015. http://www.ema.europa.eu/ . Accessed 9 Nov 2015. 
26. Amgen Inc. Repatha (evolocumab) injection, for subcutaneous use: US prescribing information. 2015. http://pi.amgen.com/ united_states/repatha/repatha_pi_hcp_english.pdf. Accessed 9 Nov 2015.

27. Health Canada. Repatha (evolocumab) solution for subcutaneous injection: Canadian product monograph. 2015. http://www.hc-sc. gc.ca/. Accessed 9 Nov 2015.

28. Balshem H, Helfand M, Schünemann HJ, Oxman AD, Kunz R, Brozek J, et al. GRADE guidelines: 3 . Rating the quality of evidence. Journal of clinical epidemiology. 2011;64(4):401-6. DOI: 10.1016/j.jclinepi.2010.07.015

29. Blom DJ, Hala T, Bolognese M, Lillestol MJ, Toth PD, Burgess L, et al. A 52-week placebo-controlled trial of evolocumab in hyperlipidemia. New England Journal of Medicine. 2014;370(19):1809-19. DOI: 10.1056/NEJMoa1316222

30. Hirayama A, Honarpour N, Yoshida M, Yamashita S, Huang F, Wasserman SM, et al. Effects of evolocumab (AMG 145), a monoclonal antibody to PCSK9, in hypercholesterolemic, statin-treated Japanese patients at high cardiovascular risk. Circulation Journal. 2014;78(5):1073-82. DOI: 10.1253/circj.CJ-14-0130

31. Koren MJ, Giugliano RP, Raal FJ, Sullivan D, Bolognese M, Langslet G, et al. Efficacy and safety of longer-term administration of evolocumab (AMG 145 ) in patients with hypercholesterolemia 52-week results from the open-label study of long-term evaluation against LDL-C (OSLER) randomized trial. Circulation. 2014;129(2):234-43. DOI: 10.1161/CIRCULATIONAHA.113.007012

32. Koren MJ, Scott R, Kim JB, Knusel B, Liu T, Lei L, et al. Efficacy, safety, and tolerability of a monoclonal antibody to proprotein convertase subtilisin/kexin type 9 as monotherapy in patients with hypercholesterolaemia (MENDEL): a randomised, double-blind, placebo-controlled, phase 2 study. The Lancet. 2012;380(9858):1995-2006. DOI: 10.1016/S0140-6736(12)61771-1

33. Raal F, Scott R, Somaratne R, Bridges I, Li G, Wasserman SM, et al. Low-Density Lipoprotein Cholesterol-Lowering Effects of AMG 145, a Monoclonal Antibody to Proprotein Convertase Subtilisin/Kexin Type 9 Serine Protease in Patients With Heterozygous Familial Hypercholesterolemia The Reduction of LDL-C With PCSK9 Inhibition in Heterozygous Familial Hypercholesterolemia Disorder (RUTHERFORD) Randomized Trial. Circulation. 2012;126(20):2408-17. DOI: 10.1161/CIRCULATIONAHA.112.144055

34. Raal FJ, Honarpour N, Blom DJ, Hovingh GK, Xu F, Scott R, et al. Inhibition of PCSK9 with evolocumab in homozygous familial hypercholesterolaemia (TESLA Part B): a randomised, double-blind,

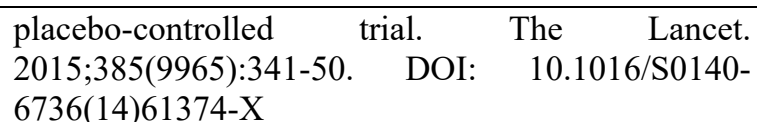

35. Koren MJ, Lundqvist P, Bolognese M, Neutel JM, Monsalvo ML, Yang J, et al. Anti-PCSK9 monotherapy for hypercholesterolemia: the MENDEL-2 randomized, controlled phase III clinical trial of evolocumab. Journal of the American College of Cardiology. 2014;63(23):2531-40. DOI: 10.1016/j.jacc.2014.03.018

36. Raal FJ, Stein EA, Dufour R, Turner T, Civeira F, Burgess L, et al. PCSK9 inhibition with evolocumab (AMG 145) in heterozygous familial hypercholesterolaemia (RUTHERFORD-2): a randomised, double-blind, placebo-controlled trial. The Lancet. 2015;385(9965):331-40. DOI: 10.1016/S0140-6736(14)61399-4

37. Henderson R, O'Kane M, McGilligan V, Watterson $\mathrm{S}$. The genetics and screening of familial hypercholesterolaemia. Journal of biomedical science. 2016; 23(1):1. DOI: 10.1186/s12929-0160256-1

38. Sullivan D, Olsson AG, Scott R, Kim JB, Xue A, Gebski V, et al. Effect of a monoclonal antibody to PCSK9 on low-density lipoprotein cholesterol levels in statin-intolerant patients: the GAUSS randomized trial. Journal of the American Medical Association. 2012; 308(23):2497-506. DOI: 10.1001/jama.2012.25790

39. Giugliano RP, Desai NR, Kohli P, Rogers WJ, Somaratne R, Huang F, et al. Efficacy, safety, and tolerability of a monoclonal antibody to proprotein convertase subtilisin/kexin type 9 in combination with a statin in patients with hypercholesterolaemia (LAPLACE-TIMI 57): a randomised, placebocontrolled, dose-ranging, phase 2 study. The Lancet. 2012; 380(9858):2007-17. DOI: 10.1016/S01406736(12)61770-X

40. Robinson JG, Nedergaard BS, Rogers WJ, Fialkow J, Neutel JM, Ramstad D, et al. Effect of evolocumab or ezetimibe added to moderate-or high-intensity statin therapy on LDL-C lowering in patients with hypercholesterolemia: the LAPLACE-2 randomized clinical trial. Journal of the American Medical Association. 2014;311(18):1870-83. DOI: 10.1001/jama.2014.4030

41. Stroes E, Colquhoun D, Sullivan D, Civeira F, Rosenson RS, Watts GF, et al. Anti-PCSK9 antibody effectively lowers cholesterol in patients with statin intolerance: the GAUSS-2 randomized, placebocontrolled phase 3 clinical trial of evolocumab. Journal of the American College of Cardiology. 2014;63(23):2541-8. DOI: 10.1016/j.jacc.2014.03.01 
Table 3. Assessment of the quality of evidence using the Grading of Recommendations Assessment, Development and Evaluation (GRADE) approach. RCT: Randomized Controlled Trial.

\begin{tabular}{|c|c|c|c|c|c|c|c|c|c|c|c|}
\hline \multicolumn{7}{|c|}{ Quality assessment } & \multicolumn{2}{|c|}{ No of patients } & \multicolumn{2}{|r|}{ Effect } & \multirow[b]{2}{*}{ Quality } \\
\hline $\begin{array}{l}\text { No of } \\
\text { studie } \\
\quad \mathrm{S}\end{array}$ & Design & $\begin{array}{l}\text { Risk of } \\
\text { bias }\end{array}$ & $\begin{array}{c}\text { Inconsistenc } \\
\mathrm{y}\end{array}$ & $\begin{array}{c}\text { Indirectnes } \\
\mathrm{s}\end{array}$ & Imprecision & $\begin{array}{c}\text { Other } \\
\text { consideration } \\
\text { s }\end{array}$ & $\begin{array}{c}\text { Evolocuma } \\
\text { b therapy }\end{array}$ & $\begin{array}{c}\text { Placeb } \\
\text { o }\end{array}$ & $\begin{array}{c}\text { Relative } \\
(95 \% \\
\text { CI })\end{array}$ & Absolute & \\
\hline \multicolumn{12}{|c|}{ Total Cholesterol (TC) } \\
\hline 6 & $\mathrm{RCT}$ & $\begin{array}{c}\text { not } \\
\text { serious }\end{array}$ & not serious & not serious & not serious & None & 1522 & 873 & - & $\begin{array}{c}\text { Decreased } 35.08 \% \\
(95 \% \mathrm{CI}=-38.34 \text { to }- \\
31.81)\end{array}$ & High \\
\hline \multicolumn{12}{|c|}{ Low-density lipoprotein Cholesterol (LDL-C) } \\
\hline 8 & $\mathrm{RCT}$ & $\begin{array}{c}\text { not } \\
\text { serious }\end{array}$ & not serious & not serious & not serious & None & 1785 & 970 & - & $\begin{array}{c}\text { Decreased } 54.71 \% \\
(95 \% \text { CI }=-59.39 \text { to }- \\
50.03)\end{array}$ & High \\
\hline \multicolumn{12}{|c|}{ High-density lipoprotein Cholesterol (HDL-C) } \\
\hline 8 & $\mathrm{RCT}$ & $\begin{array}{c}\text { not } \\
\text { serious }\end{array}$ & not serious & not serious & not serious & None & 1785 & 970 & - & $\begin{array}{c}\text { Increased } 6.06 \% \\
(95 \% \mathrm{CI}=4.7 \text { to } 7.43)\end{array}$ & High \\
\hline \multicolumn{12}{|c|}{ Very Low-density Lipoprotein Cholesterol (VLDL-C) } \\
\hline 5 & RCT & $\begin{array}{c}\text { not } \\
\text { serious }\end{array}$ & not serious & not serious & not serious & None & 886 & 497 & - & $\begin{array}{c}\text { Decreased } 28.37 \% \\
(95 \% \mathrm{CI}=-36.7 \text { to }- \\
20.04)\end{array}$ & High \\
\hline \multicolumn{12}{|c|}{ Ratio of TC to HDL-C } \\
\hline 7 & $\mathrm{RCT}$ & $\begin{array}{c}\text { not } \\
\text { serious }\end{array}$ & not serious & not serious & not serious & None & 1632 & 892 & - & $\begin{array}{c}\text { Decreased } 39.14 \% \\
(95 \% \text { CI }=-43.34 \text { to - } \\
34.95)\end{array}$ & High \\
\hline \multicolumn{12}{|c|}{ Triglycerides (TG) } \\
\hline 7 & $\mathrm{RCT}$ & $\begin{array}{c}\text { not } \\
\text { serious }\end{array}$ & not serious & not serious & not serious & None & 1049 & 602 & - & $\begin{array}{c}\text { Decreased } 12.11 \% \\
(95 \% \mathrm{CI}=-16.05 \text { to }- \\
8.16)\end{array}$ & High \\
\hline
\end{tabular}


J Pharm Pharm Sci (www.cspsCanada.org) 20, 81 - 96, 2017 